Research Article

\title{
A Study on the Effect of Hollow Tubular Flange Sections on the Behavior of Cold-Formed Steel Built-Up Beams
}

\author{
Balaji Shanmugam $\left(D,{ }^{1}\right.$ Manikandan Palanisamy $\left(\mathbb{D},{ }^{2}\right.$ Paul O. Awoyera $\left(\mathbb{D},{ }^{3}\right.$ \\ Senthilnathan Chinnasamy, ${ }^{1}$ and Mahalakshmi Subramaniam ${ }^{1}$ \\ ${ }^{1}$ Department of Civil Engineering, Kongu Engineering College, Perundurai 638060, Tamil Nadu, India \\ ${ }^{2}$ Department of Civil Engineering, Sona College of Technology, Salem 636005, Tamil Nadu, India \\ ${ }^{3}$ Department of Civil Engineering, Covenant University, PMB 1023, Ota, Nigeria
}

Correspondence should be addressed to Balaji Shanmugam; er.shbalaji@gmail.com

Received 30 June 2021; Accepted 2 September 2021; Published 27 September 2021

Academic Editor: Rahul V. Ralegaonkar

Copyright (c) 2021 Balaji Shanmugam et al. This is an open access article distributed under the Creative Commons Attribution License, which permits unrestricted use, distribution, and reproduction in any medium, provided the original work is properly cited.

\begin{abstract}
This paper deals with a study conducted on flexural behavior of cold-formed steel built-up I-beams with hollow tubular flange sections. There were two types of test sections, namely, built-up sections that were assembled with either stiffened or unstiffened channels coupling back-to-back at the web and a hollow tubular rectangular flange at the top and bottom of the web to form builtup I-beam. The flexural behavior along with the strength and failure modes of the built-up sections was examined using the fourpoint loading system. Nonlinear finite element (FE) models were formulated and validated with the experimental test results. It was observed that the developed FE models had precisely predicted the behavior of built-up I-beams. Further, the verified FE models were used to conduct a detailed parametric study on cold-formed steel built-up beam sections with respect to thickness, depth, and yield stress of the material. The flexural strength of the beams was designed using the direct strength method as specified in American Iron and Steel Institute (AISI) for the design of cold-formed steel structural members and was compared with the experimental results and the failure loads predicted from FE models. Since the results were not conservative, a new customized design equation had been mooted and delineated in the study for determining the flexural strength of cold-formed steel built-up beams with hollow tubular flange sections.
\end{abstract}

\section{Introduction}

Cold-formed steel (CFS) sections have been transformed as inherent elements in the construction and building industry due to CFS products that have a larger strength to weight ratio, enhanced stiffness, mass production, and speedy and simple installation $[1,2]$. With the advent of aluminum/zinc coating, the applications of CFS sections have become widespread across the world. The CFS built-up sections commonly have single or double symmetric shapes with stiffening lips on flanges and unstiffened or stiffened webs.

Quite a large number of investigations have been carried out in the recent past on the behavior and design of CFS beams under different loading conditions. Wang et al. [3] have optimized the cross-sectional shapes of CFS beams and beam-columns by considering the axial load and the bending moment for a single-symmetric section. Yuan et al. [4] and Moen and Schafer [5] have investigated the buckling behavior of CFS beams with holes in the web. Wang and Young [6] have studied the behavior of CFS built-up section beams with different screw arrangements. Ma et al. [7] also have suggested design equations for CFS tubular beams. However, it is observed that CFS hollow flange built-up sections are structurally more competent than the usual open channel sections [8]. The flexural performance of conventional built-up sections can be enhanced by means of hollow flange sections as a large amount of mass is placed away from the strong section axis [9].

In early 1990s, the hollow flange beams with better buckling capacities for their distinct shape were first 
introduced in Australia [10]. Besides, these sections performed well against distortional buckling because of the existence of rigid hollow flange sections at the top and bottom of the web. The cold-formed hollow flange steel section is believed to have the benefits of both hot-rolled and conventional CFS sections [11]. There are only a few research studies that have been carried out on the behavior of rectangular [12-16] and triangular hollow flange sections [17-19]. Keerthan et al. [2] have suggested the equations of design to predict the web crippling capacity of hollow flange beam sections.

The hollow flange CFS sections are usually fabricated either by cold-forming a single steel sheet to a preferable shape or by merely connecting three steel elements. The former process is quite complicated compared with the latter because the hollow flange elements are well-connected (top and bottom of the web) and secured by means of rivet/screw or spot welding. In addition, the latter with different grades and thickness can be used for T-section (web and flange) [8]. Furthermore, the residual stresses and initial geometric imperfections which differ from common hot-rolled and CFS may be introduced if the sections are fabricated by coldforming a single sheet [2].

In the present investigation, an effort has been made to explore the flexural behavior of CFS hollow tubular flange built-up I-beam sections. The beam consists of both stiffened and unstiffened channels that are connected back-to-back so as to form a web and a flange at the top and the bottom. Nonlinear FE models are developed for the proposed sections using FEA software ANSYS to confirm the results of the experimental test. A detailed parametric study is performed using the FE model with respect to material factors such as yield stress, section thickness, and depth of the beam. As per the citations of the AISI standard [20], using direct strength method (DSM), the estimated strength of the beams is compared with the experimental results and the failure load prediction from FE models.

\section{Experimental Study}

2.1. Hollow Tubular Flange I-Beam Sections. The beams were fabricated in two stages; initially, the channel sections were made by cold-forming a single sheet using press-braking process and then the two channel sections were connected together (back-to-back) with structural bolts to form the web of the I-section. Later on, the rectangular hollow tubular cold-rolled sections were linked above and beneath the web by self-threaded screws. Both the web and the flange were made up of steel with $1.6 \mathrm{~mm}$ thickness, and the geometries were attached so as to satisfy the standards given in the DSM of CFS design as shown in Figure 1. The fasteners were fixed both in the web and the flange at a uniform spacing of $140 \mathrm{~mm}$. The spacing of the fasteners was designed by considering the spacing requirements of AISI specifications [20]. The nominal diameter of the screw and the bolt was $4.8 \mathrm{~mm}$ and $10 \mathrm{~mm}$, respectively. The position of the fasteners across the cross section of the beam is shown in Figure 2 . The study was conducted in two test series, wherein stiffened and unstiffened web sections were examined with three different web aspect ratios (web length to web depth) such as $6,7.5$, and 10 per test series. The beam length was $1500 \mathrm{~mm}$, and the specimens were labeled so that the web (stiffened or unstiffened) and the depth of the beam could easily be identified. For instance, the label with USW 300 denotes the unstiffened web specimen with the overall depth of $300 \mathrm{~mm}$. The details of the test specimens are shown in Table 1. The material properties are determined by the tensile coupon test, and the average values that are recorded in the test are presented in Table 2. Those properties were used in the later part of the study for numerical investigation and strength calculation.

2.2. Test Set-Up and Instrumentation. A four-point flexural loading system was employed for testing the specimens. The ends of the beams were placed on a roller and pinned support, respectively, so as to provide a simply supported condition. The distance between the supports was $1400 \mathrm{~mm}$. The test was conducted with the loading frame of $1000 \mathrm{kN}$. Three linear variable displacement transducers (LVDTs) were utilized to measure the in-plane vertical displacements; one at the midspan section of the beam and the other two under the loading points. One of the LVDTs is used to measure the lateral deformation of the web at midspan section as shown in Figure 3. A number of strain gauges are instrumented across the cross section as shown in Figure 4 at the midspan of the beam to record the longitudinal strains. Initially, a trivial load was applied on the beam to allow the loading and support arrangement to adjust uniformly on the bearings. The load was applied gradually by a hydraulic jack and monitored by a load cell. The entire set-up was associated to a data acquisition system where the load, displacement, and strain readings were recorded at even intervals throughout the test. As the test was employed to examine the in-plane deformation under the load, restraints were provided to prevent out-of-plane movement at the supports and at the loading points. Additionally, steel cushion plates of $6 \mathrm{~mm}$ thickness were placed at the loading and at the supports to avoid stress concentration in those points.

\section{Numerical Investigation}

A nonlinear FE analysis has been carried out using ANSYS software to predict the performance of the proposed hollow flange built-up sections. Four nodded SHELL 181 elements (with midline offset option) were used to model the beam section and the steel bearings at the supports and at the loading points. Based on the limitations of the model, a $10 \mathrm{~mm}$ mesh size was brought into the proposed study. For modeling the connections (Figure 5), coupling option was used [21-23]. As suggested by Manikandan et al. [24], two types of analyses, namely, eigenvalue buckling analysis and static nonlinear buckling analysis were employed. Eigenvalue buckling analysis was used to find the buckling loads and the corresponding buckling modes of the beam, whereas the material and geometric nonlinearity were included in the 


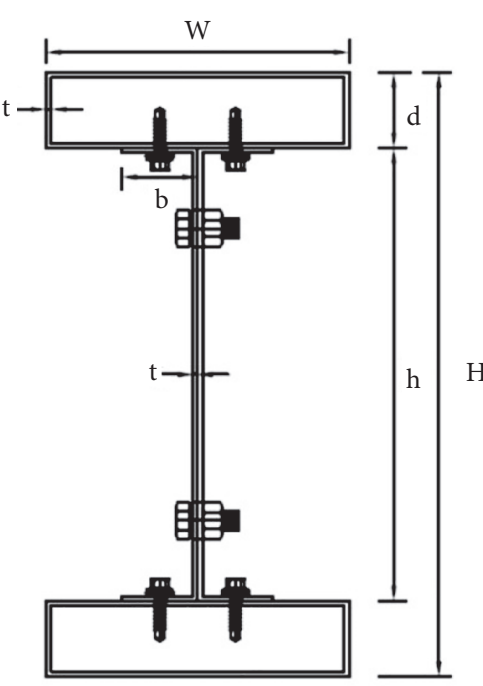

(a)

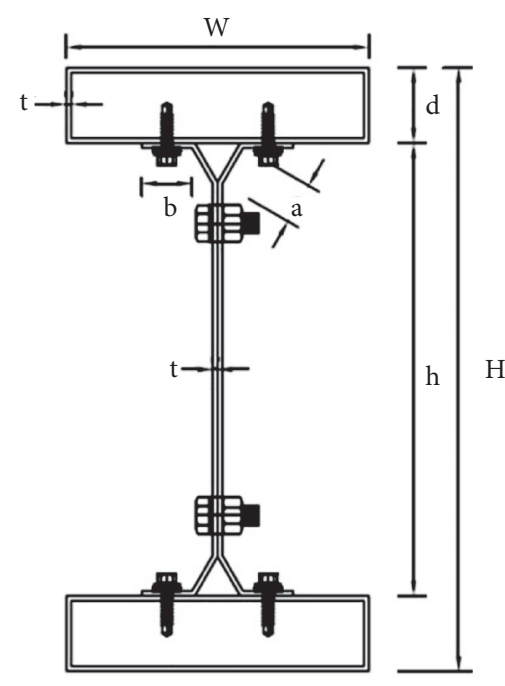

(b)

Figure 1: Section geometries: (a) unstiffened beam section; (b) stiffened beam section.

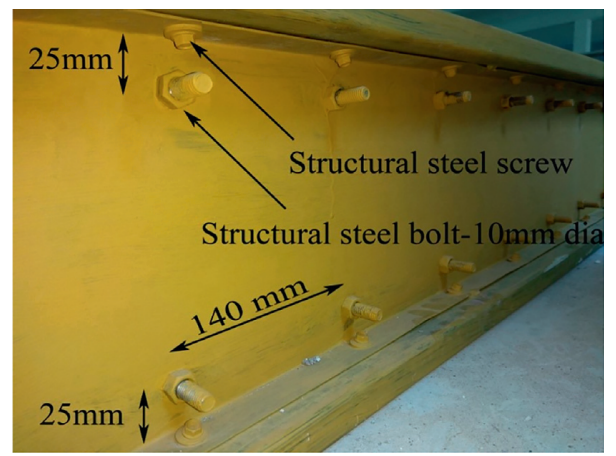

FIGURE 2: Longitudinal profile indicating the location of fasteners.

TABle 1: Specimen details.

\begin{tabular}{|c|c|c|c|c|c|c|c|c|}
\hline \multirow{2}{*}{ Specimen } & \multirow{2}{*}{ Length (mm) } & \multicolumn{7}{|c|}{ Section dimensions } \\
\hline & & $w(\mathrm{~mm})$ & $d(\mathrm{~mm})$ & $t(\mathrm{~mm})$ & $a(\mathrm{~mm})$ & $b(\mathrm{~mm})$ & $h(\mathrm{~mm})$ & $H(\mathrm{~mm})$ \\
\hline 200 USW & 1500 & 100 & 25 & 1.6 & - & 25 & 150 & 200 \\
\hline 250USW & 1500 & 100 & 25 & 1.6 & - & 25 & 200 & 250 \\
\hline 300USW & 1500 & 100 & 25 & 1.6 & - & 25 & 250 & 300 \\
\hline 200SW & 1500 & 100 & 25 & 1.6 & 17.5 & 17.5 & 150 & 200 \\
\hline 250SW & 1500 & 100 & 25 & 1.6 & 17.5 & 17.5 & 200 & 250 \\
\hline 300SW & 1500 & 100 & 25 & 1.6 & 17.5 & 17.5 & 250 & 300 \\
\hline
\end{tabular}

TABle 2: Material properties.

\begin{tabular}{lccc}
\hline Young's modulus $\left(\mathrm{N} / \mathrm{mm}^{2}\right)$ & Ultimate tensile strength $\left(\mathrm{N} / \mathrm{mm}^{2}\right)$ & \% elongation & Yield strength $\left(\mathrm{N} / \mathrm{mm}^{2}\right)$ \\
\hline $2 \times 10^{5}$ & 310 & 15.5 & 220 \\
\hline
\end{tabular}

nonlinear buckling analysis. However, the residual stress and the effect of cold-forming operation were excluded in the analysis. For the material of nonlinearity, bilinear stressstrain curve was adopted [25]. As the geometric imperfection was not calculated in the experimental program, a value of $L / 1000$ which was suggested by $\mathrm{Xu}$ et al. [22] and Kankanamge and Mahendran [26] was brought into the static nonlinear buckling analysis. A complete FE model of a hollow flange beam section with bearing plates (at loading points and supports) is shown in Figure 6. 


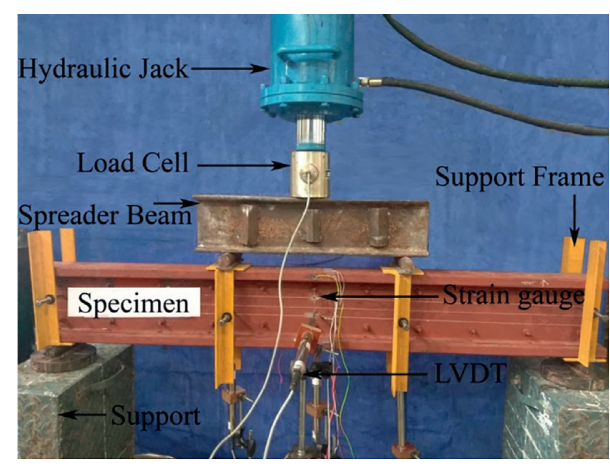

Figure 3: Test set-up and instrumentation.

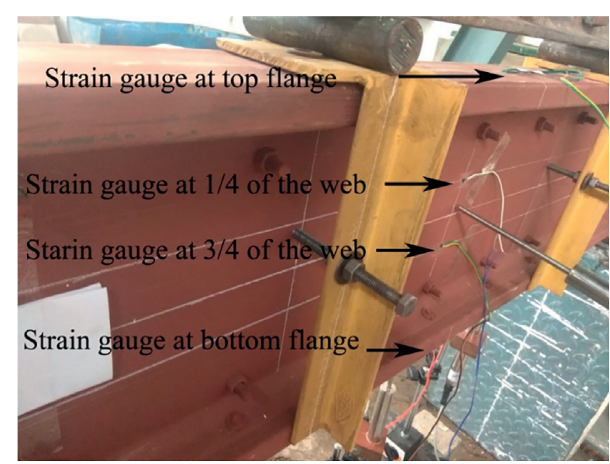

FIgURE 4: Position of strain gauges for strain measurements.

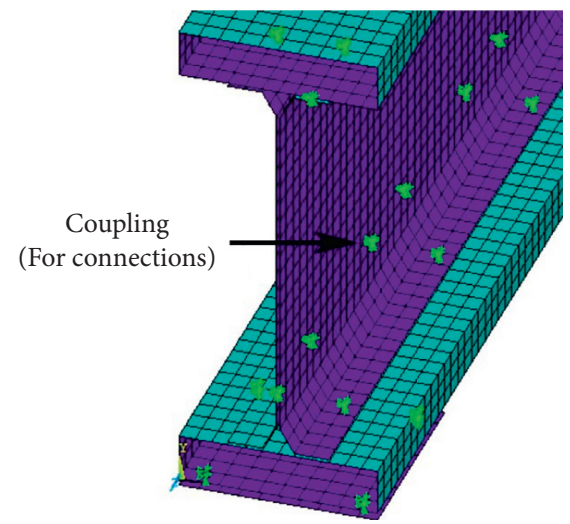

Figure 5: Connections in the FE model.

\section{Theoretical Investigation}

The values from experimental $\left(M_{\mathrm{EXP}}\right)$ and numerical investigations $\left(M_{\text {ANSYS }}\right)$ were compared with the flexural strength $\left(M_{\mathrm{DSM}}\right)$ computed from the direct strength method (DSM) using AISI specifications [20] for CFS structural members. As stated in DSM, the nominal flexural strength was the least which was considered for the buckling loads (lateral torsional, local, and distortional) and the corresponding values were calculated.

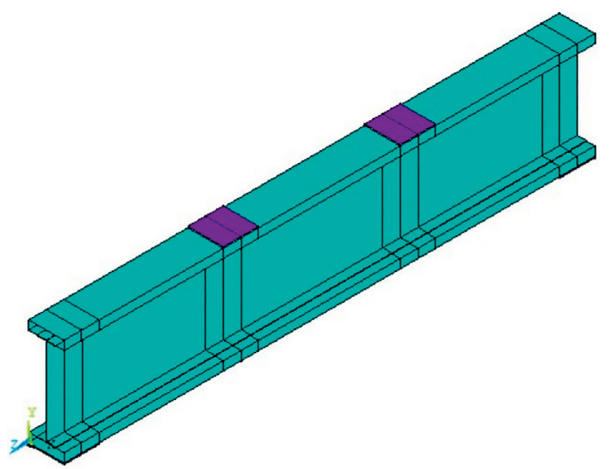

FIGURE 6: FE model with bearing plates at the supports and loading points.

\section{Results and Discussion}

The results obtained from experimental investigation, FE analysis, and design strength of DSM are reported in Table 3. The load-deflection response of unstiffened beam sections is shown in Figure 7. As a part of the experimental investigation, longitudinal strains were recorded for all the specimens using the strain gauge mounted at different locations of the beam. For instance, the variations in longitudinal strain along with the depth of the beam at midspan for 250USW section are shown in Figure 8. The bottom flange and the lower part of the web (bottom three-forth height of the web) had demonstrated a fairly linear increase in the positive strain (due to tension) for every raise in the load, whereas the top flange and the upper part of the web (top three-fourth height of the web) had indicated a fairly linear increase in the negative strain (due to compression). Nevertheless, the variation of strain in the web section at the supports was found to be absolutely nonlinear.

Invariably, the sections with the depths of 200 and $250 \mathrm{~mm}$ had failed due to flexural buckling, and with further increase in the load, the local buckling occurs in the tension flange of the beams. However, for $300 \mathrm{~mm}$ depth, due to the effect of slender web, the failure was initiated by the local buckling of the web section, and the further increase in the load had resulted in web buckling at the supports. On account of the specimen dimensions, the detected failure modes of the beam were localized at the end sections of the beam, where the moment was almost zero. This behavior is illustrated in Figures 9 and 10, which clearly demonstrates that the sections cannot handle the localized shear failure. The figures indicate that the results of the experiment are well-matched with those of the numerical study.

The stiffened web interrupted the premature buckling of the flange. However, it is observed that the web stiffeners are closer to the flange that led to the premature bucking of web at the supports as shown in Figures 11 and 12. The web buckling has more control over the load carrying the capacity of beams when compared with the flange buckling. If the web stiffeners are close to the flange (i.e., at flange-web junction), their effectiveness get decreased. Therefore, the present study has found that the load carrying the capacity of 
Table 3: Comparison of results.

\begin{tabular}{|c|c|c|c|c|c|c|c|}
\hline \multirow{2}{*}{ Specimen } & \multicolumn{3}{|c|}{ Ultimate load $(\mathrm{kN})$} & \multirow{2}{*}{$M_{\mathrm{EXP}} / M_{\mathrm{ANSYS}}$} & \multirow{2}{*}{$M_{\mathrm{EXP}} / M_{\mathrm{DSM}}$} & \multirow{2}{*}{$M_{\mathrm{ANSYS}} / M_{\mathrm{DSM}}$} & \multirow{2}{*}{ Failure mode } \\
\hline & $M_{\mathrm{EXP}}$ & $M_{\text {ANSYS }}$ & $M_{\text {DSM }}$ & & & & \\
\hline 200 USW & 14.74 & 15.78 & 9.79 & 0.93 & 1.51 & 1.61 & $\mathrm{FLB}+\mathrm{GB}$ \\
\hline 250 USW & 12.99 & 14.35 & 10.92 & 0.91 & 1.19 & 1.31 & $\mathrm{FLB}+\mathrm{GB}$ \\
\hline 300 USW & 9.68 & 9.98 & 11.96 & 0.97 & 0.81 & 0.83 & $\mathrm{WLB}+\mathrm{GB}$ \\
\hline 200 SW & 8.96 & 9.51 & 6.28 & 0.94 & 1.43 & 1.51 & $\mathrm{FLB}+\mathrm{GB}$ \\
\hline $250 \mathrm{SW}$ & 10.78 & 10.15 & 7.83 & 1.06 & 1.38 & 1.30 & $\mathrm{FLB}+\mathrm{GB}$ \\
\hline $300 \mathrm{SW}$ & 11.14 & 11.62 & 8.70 & 0.96 & 1.28 & 1.34 & $\mathrm{WLB}+\mathrm{GB}$ \\
\hline
\end{tabular}

FLB: flange local buckling; WLB: web local buckling; and GB: global buckling.

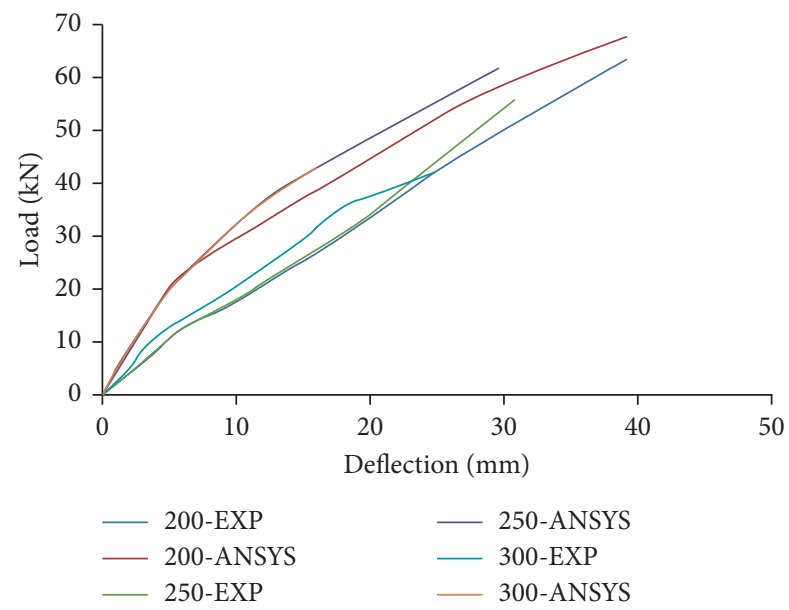

FIgURE 7: Load-deflection response of unstiffened beam sections.

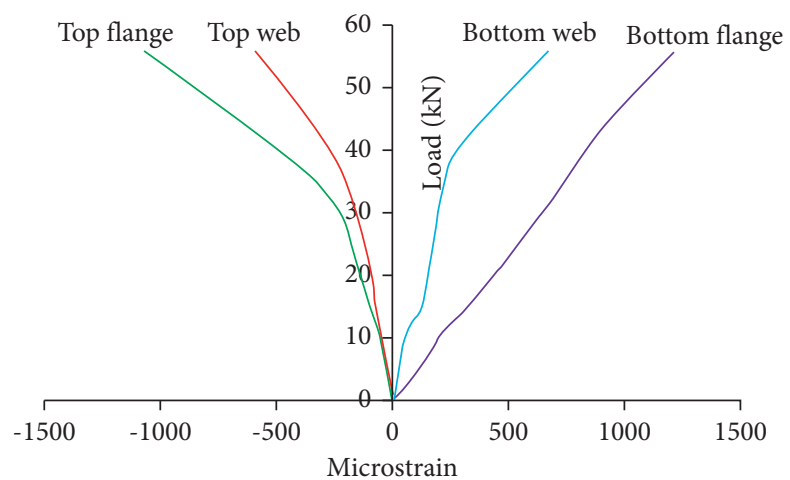

FIGURE 8: Variations in longitudinal strain along the depth of the beam at midspan for 250USW section.

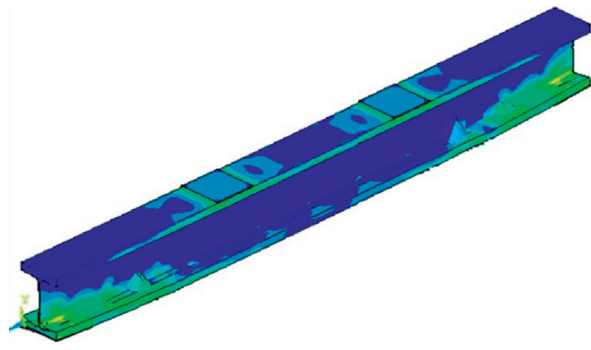

(a)

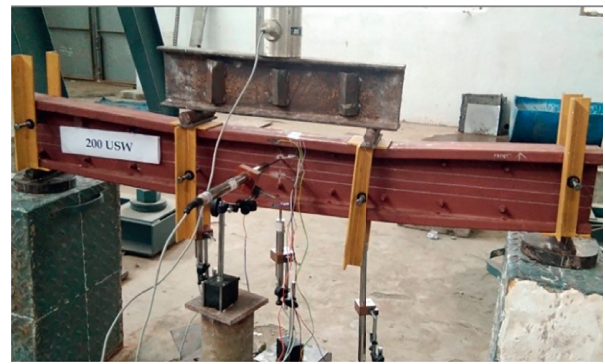

(b)

FIGURE 9: Failure mechanism of (unstiffened) 200USW beam section: (a) ANSYS; (b) experimental. 


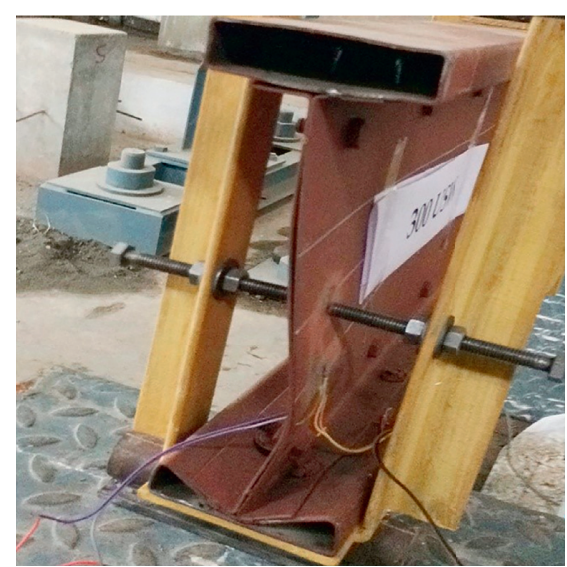

(a)

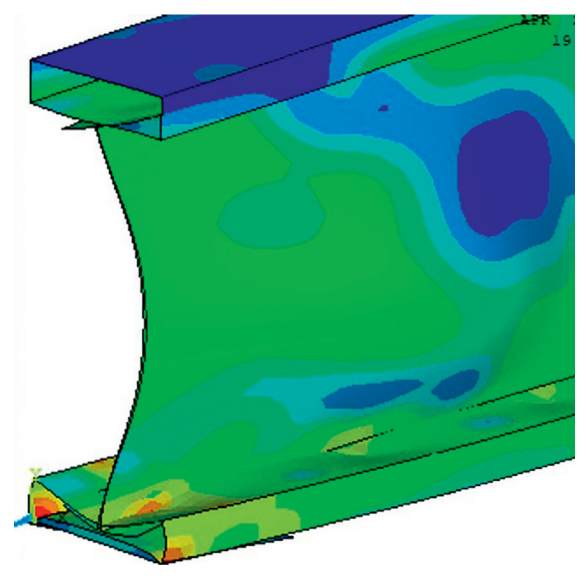

(b)

FIGURE 10: Failure mechanism of (unstiffened) 300USW beam section: (a) experimental; (b) ANSYS.

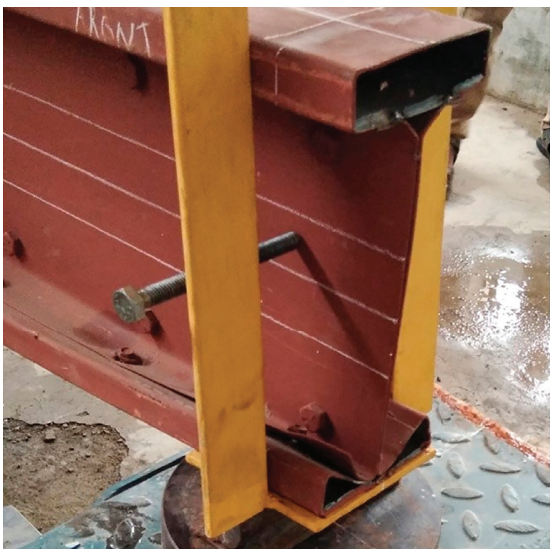

(a)

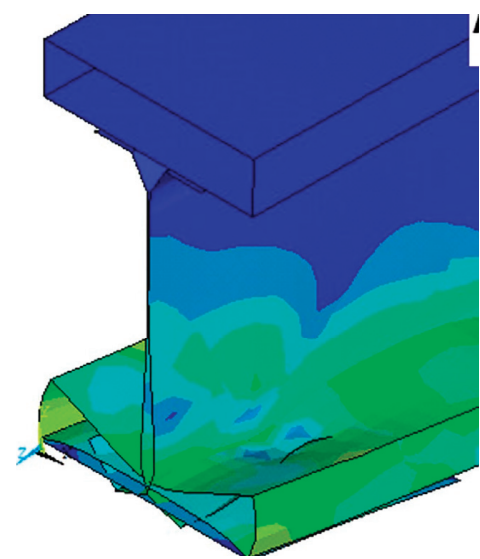

(b)

FIgURE 11: Failure mechanism of (stiffened) 200SW beam section: (a) experimental; (b) ANSYS.

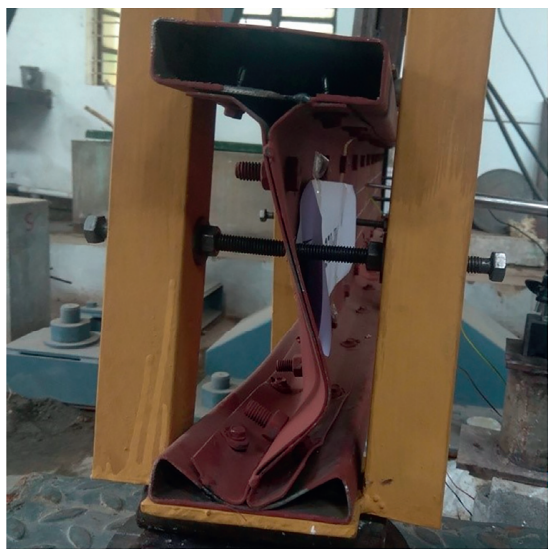

(a)

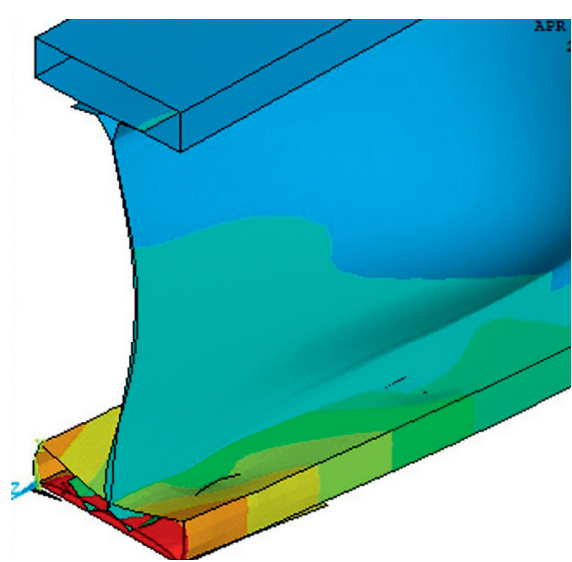

(b)

FIGURE 12: Failure mechanism of (stiffened) 300SW beam section: (a) experimental; (b) ANSYS. 
TABLE 4: Evaluation of FE analysis and DSM results.

\begin{tabular}{|c|c|c|c|c|c|c|c|c|c|}
\hline \multirow{2}{*}{ Model ID } & \multirow{2}{*}{ Depth $(\mathrm{mm})$} & \multirow{2}{*}{ Yield stress $\left(\mathrm{N} / \mathrm{mm}^{2}\right)$} & \multirow{2}{*}{ Thickness (mm) } & \multicolumn{6}{|c|}{ Flexural strength $(\mathrm{kNm})$} \\
\hline & & & & $M_{\text {ANSYS }}$ & $M_{\mathrm{DSM}}$ & $M_{\mathrm{Y}}$ & $M_{\mathrm{ANSYS}} / M_{\mathrm{DSM}}$ & $M_{\mathrm{D}}$ & $M_{\text {ANSYS }} / M_{\mathrm{D}}$ \\
\hline D200Y220T1.2 & 200 & 220 & 1.2 & 9.33 & 6.02 & 17.98 & 1.55 & 7.82 & 1.19 \\
\hline D250Y220T1.2 & 250 & 220 & 1.2 & 7.23 & 6.67 & 24.66 & 1.08 & 7.37 & 0.98 \\
\hline D300Y220T1.2 & 300 & 220 & 1.2 & 6.65 & 7.28 & 31.81 & 0.91 & 7.09 & 0.94 \\
\hline D200Y275T1.2 & 200 & 275 & 1.2 & 10.76 & 6.93 & 22.48 & 1.55 & 8.50 & 1.27 \\
\hline D250Y275T1.2 & 250 & 275 & 1.2 & 8.34 & 7.67 & 30.82 & 1.09 & 7.92 & 1.05 \\
\hline D300Y275T1.2 & 300 & 275 & 1.2 & 7.93 & 8.37 & 39.77 & 0.95 & 7.89 & 1.01 \\
\hline D200Y340T1.2 & 200 & 340 & 1.2 & 12.28 & 7.92 & 27.79 & 1.55 & 9.13 & 1.34 \\
\hline D250Y340T1.2 & 250 & 340 & 1.2 & 9.98 & 8.76 & 38.11 & 1.14 & 8.55 & 1.17 \\
\hline D300Y340T1.2 & 300 & 340 & 1.2 & 9.13 & 9.54 & 49.17 & 0.96 & 9.10 & 1.00 \\
\hline D200Y220T1.6 & 200 & 220 & 1.6 & 15.78 & 9.79 & 23.80 & 1.61 & 14.22 & 1.11 \\
\hline D250Y220T1.6 & 250 & 220 & 1.6 & 14.35 & 10.92 & 32.64 & 1.31 & 14.20 & 1.01 \\
\hline D300Y220T1.6 & 300 & 220 & 1.6 & 9.98 & 11.96 & 42.13 & 0.83 & 13.74 & 0.73 \\
\hline D200Y275T1.6 & 200 & 275 & 1.6 & 16.40 & 11.30 & 29.75 & 1.45 & 15.83 & 1.04 \\
\hline D250Y275T1.6 & 250 & 275 & 1.6 & 14.91 & 12.58 & 40.80 & 1.19 & 15.43 & 0.97 \\
\hline D300Y275T1.6 & 300 & 275 & 1.6 & 12.05 & 13.76 & 52.66 & 0.88 & 14.76 & 0.82 \\
\hline D200Y340T1.6 & 200 & 340 & 1.6 & 16.86 & 12.94 & 36.78 & 1.30 & 17.38 & 0.97 \\
\hline D250Y340T1.6 & 250 & 340 & 1.6 & 15.33 & 14.38 & 50.44 & 1.07 & 16.58 & 0.92 \\
\hline D300Y340T1.6 & 300 & 340 & 1.6 & 14.39 & 15.71 & 65.11 & 0.92 & 15.84 & 0.91 \\
\hline D200Y220T2.0 & 200 & 220 & 2 & 22.81 & 14.19 & 29.52 & 1.61 & 21.63 & 1.05 \\
\hline D250Y220T2.0 & 250 & 220 & 2 & 21.70 & 15.92 & 40.51 & 1.36 & 22.67 & 0.96 \\
\hline D300Y220T2.0 & 300 & 220 & 2 & 21.14 & 15.74 & 47.07 & 1.34 & 20.47 & 1.03 \\
\hline D200Y275T2.0 & 200 & 275 & 2 & 23.33 & 16.42 & 36.90 & 1.42 & 24.52 & 0.95 \\
\hline $\mathrm{D} 250 \mathrm{Y} 275 \mathrm{~T} 2.0$ & 250 & 275 & 2 & 23.25 & 18.36 & 50.63 & 1.27 & 25.10 & 0.93 \\
\hline D300Y275T2.0 & 300 & 275 & 2 & 22.15 & 18.14 & 58.83 & 1.22 & 22.25 & 1.00 \\
\hline D200Y340T2.0 & 200 & 340 & 2 & 23.61 & 18.84 & 45.62 & 1.25 & 27.41 & 0.86 \\
\hline $\mathrm{D} 250 \mathrm{Y} 340 \mathrm{~T} 2.0$ & 250 & 340 & 2 & 23.47 & 21.02 & 62.60 & 1.12 & 27.41 & 0.86 \\
\hline D300Y340T2.0 & 300 & 340 & 2 & 22.37 & 20.73 & 72.74 & 1.08 & 23.90 & 0.94 \\
\hline Mean & & & & & & & 1.22 & & 1.00 \\
\hline Standard deviati & & & & & & & 0.24 & & 0.13 \\
\hline
\end{tabular}

unstiffened beam is superior than the stiffened beam section. Similar type of behavior was observed by Manikandan and Sukumar [25], wherein the strength of built-up I-beam along with stiffened channel sections (connected back-to-back) was found to be less than the beams with unstiffened channel sections.

\section{Parametric Study}

A detailed parametric study was done with the aid of the verified FE model to calculate the strength and flexural behavior of the hollow flange built-up beam sections. The parametric study was conducted only for the unstiffened hollow flange beam sections as the stiffened web sections did not have any considerable effect on the flexural capacity of beams. Yield stress, depth, and the thickness of the section were considered as variable parameters whilst the beam length and bolt spacing remained constant. The yield stress of the material was taken as $220 \mathrm{~N} / \mathrm{mm}^{2}, 275 \mathrm{~N} / \mathrm{mm}^{2}$, and $340 \mathrm{~N} / \mathrm{mm}^{2}$, whereas the thickness of the sections was taken as $1.2 \mathrm{~mm}, 1.6 \mathrm{~mm}$, and $2 \mathrm{~mm}$. A total number of $27 \mathrm{FE}$ models were analyzed in the parametric study. The results and their comparisons with theoretical investigation are presented in Table 4. It can be observed that the DSM values $\left(M_{\mathrm{DSM}}\right)$ were not conservative with the results of FEA ( $\left.M_{\text {ANSYS }}\right)$. The DSM method had underestimated the flexural strength of cold-formed steel built-up beams with hollow rectangular flange sections. The average value of $M_{\text {ANSYS }} / M_{\text {DSM }}$ ratio was equal to 1.22 with a standard deviation of 0.24 . Hence, in this investigation, a new customized design curve (shown in Figure 13) and a design formula (given in equation (1)) are proposed to determine the flexural strength of cold-formed steel built-up beams with hollow rectangular flange sections. The design flexural strength $\left(M_{\mathrm{D}}\right)$ was calculated using the proposed design equation, and the average value of $M_{\mathrm{ANSY}} / M_{\mathrm{D}}$ ratio was equal to 1.00 with a standard deviation of 0.13 . The design flexural strength had agreed well with the results of FEA.

Further, it can be noticed that the yield stress, depth, and the thickness of the material have a significant influence on the strength of the section. However, it is observed that the web aspect ratio does not have a significant effect on the load carrying capacity of beams at higher thickness and yield stress. 


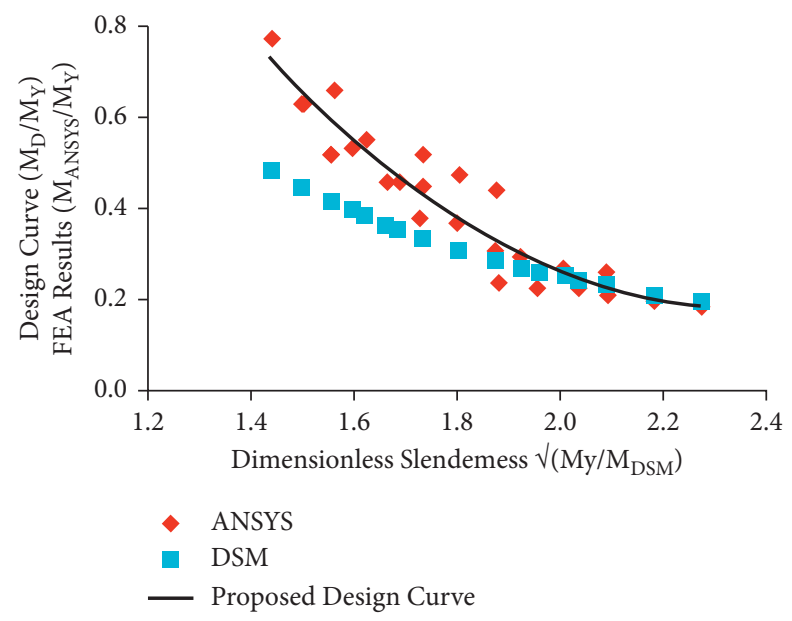

FIgURE 13: Design curve.

$$
M_{\mathrm{D}}= \begin{cases}M_{\mathrm{Y}}, & \text { for } \lambda_{\mathrm{d}} \leq 1.4, \\ M_{\mathrm{Y}}\left(0.697\left(\frac{M_{\mathrm{Y}}}{M_{\mathrm{DSM}}}\right)-3.24\left(\sqrt{\frac{M_{\mathrm{Y}}}{M_{\mathrm{DSM}}}}\right)+3.96\right), & \text { for } \lambda_{\mathrm{d}}>1.4,\end{cases}
$$

where

$M_{\mathrm{DSM}}$ is the flexural strength using the direct design method

$M_{\mathrm{Y}}$ is the yield strength

$M_{\mathrm{D}}$ is the design flexural strength

$\lambda_{\mathrm{d}}=\sqrt{M_{\mathrm{Y}} / M_{\mathrm{DSM}}}$

\section{Conclusions}

In this work, a detailed investigation has been carried out on the flexural behavior of built-up CFS beams with hollow tubular flange sections, and the following inferences are drawn:

(1) Due consideration has to be given to web buckling and web aspect ratio in the design of hollow tubular flange CFS built-up section.

(2) Simple web stiffeners do not have any significant effect on the load carrying capacity. The web stiffeners that are closer to the flange (flange/web junction) led to premature buckling of the web at the supports.

(3) The yield stress, thickness, depth, and web aspect ratio of the section play a substantial role in the flexural capacity of the beam.

(4) The experimental results are well-compared with the numerical study. However, geometric imperfection may be the reason for the minor difference in the values. The failure mode prediction by FE models is matched exactly with the experimental test results.

(5) Flexural strength of the beams, designed using AISI specification [20], is mismatched with the experimental results and the failure load prediction (FE models). Hence, the customized design equation has been mooted and delineated in this study to determine the flexural strength of cold-formed steel built-up beams with hollow tubular flange sections.

\section{Data Availability}

The "Experimental Research" data used to support the findings of this study are available from the corresponding author upon request.

\section{Conflicts of Interest}

The authors declare that there are no conflicts of interest.

\section{References}

[1] L. Sundararajah, M. Mahendran, and P. Keerthan, "Web crippling experiments of high strength lipped channel beams under one-flange loading," Journal of Constructional Steel Research, vol. 138, pp. 851-866, 2017.

[2] P. Keerthan, M. Mahendran, and E. Steau, "Experimental study of web crippling behaviour of hollow flange channel beams under two flange load cases," Thin-Walled Structures, vol. 85, pp. 207-219, 2014.

[3] B. Wang, G. L. Bosco, B. P. Gilbert, H. Guan, and L. H. Teh, "Unconstrained shape optimisation of singly-symmetric and open cold-formed steel beams and beam-columns," ThinWalled Structures, vol. 104, pp. 54-61, 2016.

[4] W.-b. Yuan, N.-t. Yu, and L.-y. Li, "Distortional buckling of perforated cold-formed steel channel-section beams with circular holes in web," International Journal of Mechanical Sciences, vol. 126, pp. 255-260, 2017. 
[5] C. D. Moen and B. W. Schafer, "Elastic buckling of coldformed steel columns and beams with holes," Engineering Structures, vol. 31, no. 12, pp. 2812-2824, 2009.

[6] L. Wang and B. Young, "Behaviour and design of cold-formed steel built-up section beams with different screw arrangements," Thin-Walled Structures, vol. 131, pp. 16-32, 2018.

[7] J.-L. Ma, T.-M. Chan, and B. Young, "Design of cold-formed high strength steel tubular beams," Engineering Structures, vol. 151, pp. 432-443, 2017.

[8] S. Kesawan, M. Mahendran, Y. Dias, and W.-B. Zhao, "Compression tests of built-up cold-formed steel hollow flange sections," Thin-Walled Structures, vol. 116, pp. 180-193, 2017.

[9] N. Tondini and A. Morbioli, "Cross-sectional flexural capacity of cold-formed laterally-restrained steel rectangular hollow flange beams," Thin-Walled Structures, vol. 95, pp. 196-207, 2015.

[10] One Steel Australian Tube Mills (OATM), Design of Lite Steel Beams, One Steel Australian Tube Mills (OATM), Brisbane, Australia, 2008.

[11] R. I. Dempsey, "Structural behaviour and design of hallow flange beams," in Proceedings of the 2nd National Structural Engineering Conference, pp. 327-335, Institution of Engineers, Adelaide, Australia, January 1990.

[12] S. Kesawan, V. Jatheeshan, and M. Mahendran, "Elevated temperature mechanical properties of hollow flange channel sections," Construction and Building Materials, vol. 87, pp. 86-99, 2015.

[13] S. Kesawan and M. Mahendran, "Post-fire mechanical properties of cold-formed steel hollow sections," Construction and Building Materials, vol. 161, pp. 26-36, 2018.

[14] E. Magnucka-Blandzi, "Effective shaping of cold-formed thinwalled channel beams with double-box flanges in pure bending," Thin-Walled Structures, vol. 49, no. 1, pp. 121-128, 2011.

[15] T. Anapayan and M. Mahendran, "Improved design rules for hollow flange sections subject to lateral distortional buckling," Thin-Walled Structures, vol. 50, no. 1, pp. 128-140, 2012.

[16] T. Anapayan, M. Mahendran, and D. Mahaarachchi, "Lateral distortional buckling tests of a new hollow flange channel beam," Thin-Walled Structures, vol. 49, no. 1, pp. 13-25, 2011.

[17] P. Avery and M. Mahendran, "Finite-element analysis of hollow flange beams with web stiffeners," Journal of Structural Engineering, vol. 123, no. 9, pp. 1123-1129, 1997.

[18] M. Mahendran and P. Avery, "Buckling experiments on hollow flange beams with web stiffeners," Journal of Structural Engineering, vol. 123, pp. 1130-1134, 2002.

[19] P. Avery, M. Mahendran, and A. Nasir, "Flexural capacity of hollow flange beams," Journal of Constructional Steel Research, vol. 53, no. 2, pp. 201-223, 2000.

[20] American Iron and Steel Institute, AISI-S100:Specification for the Design of Cold-Formed Steel Structural Members, American Iron and Steel Institute, Granite City, IL, USA, 2016.

[21] W.-X. Ren, S.-E. Fang, and B. Young, "Finite-element simulation and design of cold-formed steel channels subjected to web crippling," Journal of Structural Engineering, vol. 132, no. 12, pp. 1967-1975, 2006.

[22] L. Xu, P. Sultana, and X. Zhou, "Flexural strength of coldformed steel built-up box sections," Thin-Walled Structures, vol. 47, no. 6-7, pp. 807-815, 2009.

[23] M. M. Pastor and F. Roure, "Open cross-section beams under pure bending II. Finite element simulation," Thin-Walled Structures, vol. 47, no. 5, pp. 514-521, 2009.
[24] P. Manikandan, S. Balaji, S. Sukumar, and M. Sivakumar, "Experimental and numerical analysis of web stiffened coldformed steel channel column with various types of edge stiffener," International Journal of Advanced Structural Engineering, vol. 9, no. 2, pp. 129-138, 2017.

[25] P. Manikandan and S. Sukumar, "Behaviour of stiffened coldformed steel built-up sections with complex edge stiffeners under bending," KSCE Journal of Civil Engineering, vol. 19, no. 7, pp. 2108-2115, 2015.

[26] D. N. Kankanamge and M. Mahendran, "Behaviour and design of cold-formed steel beams subject to lateral-torsional buckling," Thin-Walled Structures, vol. 51, pp. 25-38, 2012. 